\title{
UN DIOS QUE SE VISTE POR LOS PIES: \\ LA VESTIMENTA PERSA EN LA ICONOGRAFÍA MITRAICA \\ A GOD THAT IS DRESSED BY THE FEET: \\ PERSIAN DRESS IN MYTHRAIC ICONOGRAPHY
}

ISRAEL CaMpos MÉNDEZ

Universidad de Las Palmas de Gran Canaria

ISRAEL.CAMPOS@ULPGC.ES

\section{RESUMEN}

La representación iconográfica del dios Mitra está vinculada a su imagen llevando un tipo de vestimenta que tradicionalmente se ha venido a denominar "vestido oriental" o "traje persa”. Dentro de esta forma de vestir, la presencia del pantalón (anaxyrides) alcanzó un cierto protagonismo, por su impacto cultural. Esta prenda había recibido una connotación peyorativa desde época griega a la hora de definir la alteridad bárbara aqueménida y posteriormente esta visión fue asumida por los romanos, trasladada a sus enemigos los partos. Son varios los po-

\section{Abstract}

The iconographic representation of the god Mithra is linked to his image wearing a type of clothing that has traditionally been called "Oriental dress" or "Persian dress". Within this way of dressing, the presence of the trousers (anaxyrides) reached a certain prominence, due to its cultural impact. This garment had received a pejorative connotation from Greek times at the moment of defining the Achaemenian barbarian alterity and later this vision was assumed by the Romans, transferred to their enemies the Parthians. There are several contexts in 
sibles contextos en los que los seguidores de Mitra pudieron asumir su presencia dentro del marco mitraico. Nos proponemos con este artículo aclarar a qué se hace referencia cuando se utiliza la categoría de "traje persa" y cuál pudo ser la reacción que desde el culto mitraico se ejerció ante una de las prendas que formaban parte de estas ropas: el pantalón. which the followers of Mithra could assume their presence within the Mithraic context. We propose with this paper to clarify what really means this category and what could be the reaction that from the Mithraic cult was exercised before one of the pieces that were part of these clothes: the trousers.

\section{PAlabras Clave}

Mitraísmo, traje persa, anaxyrides, iconografía, bárbaro

\section{KEYWORDS}

Mithraism, Persian Dress, anaxyrides, iconography, barbarian 


\section{INTRODUCCIÓN}

Una de las controversias que todavía sigue manteniendo su vigencia dentro de la historiografía mitraica es la concerniente con el esclarecimiento de la relación que debió existir entre el carácter iranio original del dios Mitra y el lugar de procedencia de lo que luego en Roma se conocería como misterios mitraicos. La hipótesis establecida por Franz Cumont ${ }^{1}$ a principios del siglo XX, quien señalaba que el mitraísmo no era sino una versión occidentalizada del culto persa de Mitra fue firmemente revisada en los años setenta por R. Gordon ${ }^{2}$ y J. Hinnells, ${ }^{3}$ posteriormente por R. Melkerbach, ${ }^{4}$ D. Ulansey ${ }^{5}$ y R. Beck. ${ }^{6}$ En los siguientes años, la discusión no solo en torno al lugar de procedencia de la práctica mistérica mitraica, sino sobre cuál pudo ser la relación que se estableció entre el modelo cultual romano y el sustrato persa generó una profusa literatura al respecto. ${ }^{7}$ Más reciente ha sido el intento por establecer cuál ha sido la percepción que desde el contexto romano se pudiera tener de todos aquellos elementos que de forma directa o indirecta hubieran sido percibidos como una clara evocación al "persianismo" de esta divinidad. En este sentido, nos resulta enorme-

1. Cumont, 1903.

2. Gordon, 1975.

3. Hinnells, 1975.

4. Merkelbach, 1984.

5. Ulansey, 1989.

6. Beck, 2004.

7. Recomendamos para una panorámica de la bibliografía específica sobre estas cuestiones mitraicas el artículo de Campos, 2017b. 
mente sugerente el marco de interpretación propuesto por R. Gordon ${ }^{8}$ al establecer un ánimo de voluntad interesada por parte de los seguidores mitraicos a la hora de introducir, mantener o subrayar todos aquellos elementos que pudieran reforzar un aire de exotismo de temática orientalizante. Situación que ha quedado demostrado ${ }^{9}$ que se produjo en torno a la introducción de manera artificial de terminología de origen persa en el contexto de las inscripciones mitraicas.

En paralelo a este intento de comprender cuáles fueron los elementos de origen persa que pudieron pervivir en el mitraísmo romano y la percepción que de ellos pudiera tenerse por parte de los iniciados en el culto, también ha sido puesta en revisión en los últimos años la categoría misma de "religión oriental" acuñada por el propio F. Cumont ${ }^{10}$ no solo para los devotos de Mitra, sino extendida a las demás modalidades cultuales desarrolladas en el Imperio Romano desde finales de la República y a lo largo del periodo imperial: Isis, Cibeles, Serapis, Dionisos, etc. El sabio belga estableció esta categoría de "religiones orientales" en un contexto romano-centrista, claramente difusionista y desde una matriz de interpretación de estos cultos en un proceso de transición hacia el triunfo final del cristianismo. En los últimos años, son varios los autores que han matizado la pertinencia del uso generalista de la expresión "orientales", ${ }^{11}$ para unas prácticas religiosas que habían pasado plenamente por el tamiz romanizador ${ }^{12}$ establecido por las autoridades políticas del Imperio y que dejaban en meramente anecdóticos o exóticos los aspectos no-romanos presentes en estos cultos.

Dentro del mitraísmo, son varios los elementos que históricamente han sido encasillados dentro de esta lista de "elementos orientales". Empezando por el propio nombre de la divinidad, que es la evidencia más clara que entronca este culto con una procedencia persa, también se han sumado otras evidencias que han aparecido en el contexto mitraico y que abundan en esta cuestión: la presencia de palabras de origen persa en inscripciones (nama, nabarze, Arimanio). Pero, de todas ellas, entendemos que la que debió presentarse ante los fieles mitraicos como un recordatorio constante de la "no-romanidad" de Mitra era la que se reflejaba en la propia imaginería establecida para este dios. El canon iconográfico mitraico que quedaba establecido en la escena central de la Tauroctonía, omnipresente en todos los espacios de culto, junto con las demás representaciones de esta divinidad en otros episodios rituales, además de los acompañantes divinos Cautes y Cautópates, establecen una figuración de Mitra

8. Gordon, 2014; Gordon, 2017.

9. Campos, 2017a.

10. Cumont, 1906.

11. Alvar, 2017, pp. 23-46.

12. Alvar, 2008; Sierra y Campos, 2010, pp. 55-66. 
vestido con unos ropajes que evocan ineludiblemente al contexto geográfico oriental del Imperio romano. Esta circunstancia debió suponer, a todas luces, un impacto visual y cultural significativo por las implicaciones que históricamente había tenido este tipo de vestimenta en el mundo griego y romano.

Puesto que los códigos de vestimenta no son neutrales, ni se pueden establecer ajenos a las implicaciones culturales de los pueblos y civilizaciones que los portan, entendemos que la representación iconográfica de Mitra con estas ropas no debió pasar de forma inadvertida a quienes se integraban en su culto. Nos proponemos en las siguientes páginas tratar de comprender cuál pudo ser la percepción que desde el contexto mitraico pudieron tener los seguidores de Mitra de cara a la asimilación y normalización de un elemento cultural visual (las vestiduras) que, fuera del espacio concreto de adoración de este dios, estaba investido, como veremos, de una carga ideológica negativa, hostil y peyorativa.

\section{2. ¿A QUÉ LLAMAMOS “VESTIDO ORIENTAL"?}

Existe un cierto consenso tanto en la historiografía moderna como en las referencias ofrecidas por los autores clásicos, en establecer una normalización de lo que sería la forma de vestir atribuida a las poblaciones que habitaban el territorio del Próximo Oriente asiático en el periodo greco-romano. Resulta particularmente interesante observar cómo ha habido un especial interés por parte de los autores griegos y romanos en describir las vestimentas llevadas por aquellos pueblos con los que habían establecido una alteridad conflictiva. En el caso griego, quedaba focalizado en los pueblos medos y persas. Para los romanos, esta relación fue transferida primero a los partos y luego a los sasánidas. Desde Heródoto (V 49; VII 61, 1) hasta los Padres de la Iglesia (Tert., De pallio 4, 6), son numerosas las referencias que encontramos a las prendas que vestían estos pueblos, con el claro interés por definir a través de ellos una identidad abiertamente opuesta a la representada por los griegos y los romanos. Quedó así establecida una fórmula que servía como referencia genérica para esta oposición cultural en los ropajes. La expresión "vestido oriental" o "traje medo" aparece en las fuentes clásicas (Hdt., I 135, 1; III 84; Arr., An. IV 4; Procop., Pers. IV 6) y ha sido normalizada en la bibliografía moderna ${ }^{13}$ para referirse a las prendas de vestir claramente diferenciadas de las usadas por los pueblos del ámbito del Mediterráneo.

13. Desde las primeras menciones aparecidas en Heuzey, 1935, pp. 85-86, ha sido luego normalizada y continuada por el resto de los autores de forma genérica hasta la actualidad: Thomson, 1965; Sekunda, 2010; Llewelyn-Jones, 2013, p. 62. 
Esta categoría de "vestido oriental" quedó establecida en torno a cinco piezas

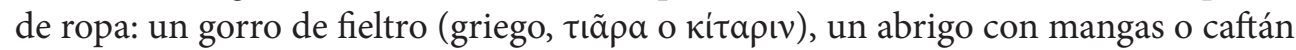

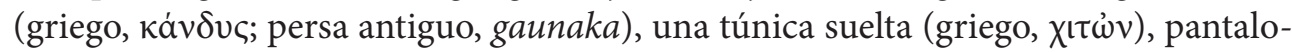

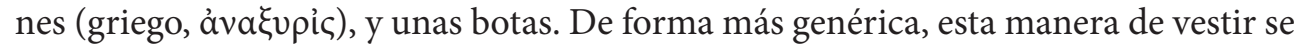
popularizó también bajo la expresión "traje medo" (Plut., Alex. 45, 2; Moralia 329f; Tert., De pallio 4, 6), puesto que los griegos atribuyeron a este pueblo la adaptación de este tipo de vestimentas, si bien otros autores como Jenofonte precisaron que estos a su vez la copiaron de los escitas, y posteriormente en época de Ciro, fue asumida como característica de los propios persas:

"Nos parece haber descubierto que Ciro no solo consideraba que los que mandan debían diferir de sus súbditos en el hecho de ser mejores que ellos, sino que además creía que debían fascinarles con actitudes teatrales. Así, no sólo él mismo adoptó la moda meda en su vestir habitual, sino que también exhortó a sus colaboradores a seguirla esta manera de vestir a él le parecía que disimulaba si alguno tenía algún defecto en su cuerpo y hacía ver a todos los que la llevaban más hermosos y más altos". ${ }^{14}$

No podemos ignorar la presencia de factores culturales y de confrontación en el proceso de cosificación de esta expresión "traje medo" o "vestidura oriental". El vestido se convierte en un mecanismo privilegiado para representar la alteridad; en este sentido, la semántica del vestido es utilizada por griegos y luego por romanos, para construir una imagen estereotipada de su representación del bárbaro persa o

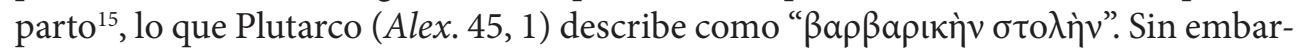
go, llegados a este punto, conviene que nos preguntemos si sigue siendo pertinente que continuemos utilizando de forma acrítica esta categoría para referirnos a esta manera de vestir. En los últimos años, son varios los autores que han hecho un llamamiento a una revisión de la perpetuación del uso de esta expresión para englobar la forma de representación del extranjero oriental en el contexto greco-romano. Tanto Miller ${ }^{16}$ como Llewelyn-Jones ${ }^{17}$ han señalado con acierto que tenemos testimonios suficientes ${ }^{18}$ que nos presentan otras muchas modas y formas de vestir de estos pueblos y aquella que ha quedado normalizada correspondía de manera puntual a lo que debería ser descrito como "ropa de montar"; por cuanto estas piezas de ropa seña-

14. Xen., An. VIII 1, 40-41 (traducción Carlos Varias, Madrid, 2006).

15. Muccioli, 2007, pp. 87-115; García Sánchez, 2009; García Sánchez, 2012, p. 13; Grand-Clément, 2013.

16. Miller, 1997, pp. 183-186.

17. Llewelyn-Jones, 2013, p. 62.

18. Armayor, 1978, pp. 5-6; Thompson, 1965; Azoulay, 2004; Ilarraga, 2017, pp. 1611-1612. 
ladas serían las que los persas habían tomado de medos y escitas como las más adecuadas para la práctica de la equitación (Strab., XI 13, 9). Es significativo que en las representaciones de los reyes persas nunca les encontremos con estas ropas, ${ }^{19}$ por lo que habría que destacar que existía claramente una distinción entre lo que sería una vestimenta real y otra ordinaria, a la que los autores griegos y romanos se referirían como la característica de los persas.

Queda claro, pues, que debemos establecer una cierta cuarentena a la hora de continuar con el uso generalista y cosificador de la expresión "vestiduras orientales" a la hora de usarlo como categoría descriptiva para referirnos a la utilización de la serie de piezas de ropa que hemos mencionado arriba. El estereotipo que se acuñó por parte de griegos y romanos para identificar al bárbaro oriental ha sido perpetuado por la historiografía moderna ${ }^{20}$ puesto que seguimos encontrando la repetición permanente de esta expresión para describir la manera en que tanto Mitra como otras divinidades (Atis, Sabazios, Orfeo, Júpiter Dolicheno) o personalidades de procedencia oriental aparecen representados en la iconografía.

\section{3. ¿QUÉ PERCEPCIÓN TENÍAN LOS GRIEGOS Y ROMANOS DEL PANTALÓN?}

Este conjunto de vestimentas ha servido para confirmar la consolidación de una imagen estereotipada y peyorativa del bárbaro oriental, particularmente del persa y luego del parto, desde la perspectiva de la identidad enfrentada a la alteridad. No obstante, existió una prenda que, de manera particular, ha recibido una mayor carga ideológica significativa en el proceso de confección del choque cultural que se puso en marcha a partir del momento en que las relaciones entre griegos y persas entraron en la esfera del conflicto, no solo militar, sino cultural e identitario. ${ }^{21} \mathrm{De}$ todas las piezas que engloban la mal llamada categoría de "vestido oriental", la presencia del pantalón (anaxyrides) es la que ha encontrado en las fuentes clásicas el mayor número de referencias con un claro componente ideológico, hasta el punto de poder ser considerada como una parte clave a la hora de representar de manera privilegiada el elemento visual más significativo de la alteridad greco-persa, primero, y luego romano-parta. El uso del anaxyrides en oposición al modelo de

19. Llewelyn-Jones, 2013, pp. 63-64.

20. Ha sido una constante comprobar cómo no ha habido un interés claro por indagar qué realidad quedaba reflejada dentro de esta expresión. Es por ese motivo que encontramos una mera repetición de la fórmula: Saxl, 1931, p. 14; Widengren, 1956, p. 234; Schneider, 1986; Ulansey, 1989, p. 25; Schneider, 2007, p. 51; García Sánchez, 2012; Yatsenko, 2013, p. 118; Gordon, 2017, p. 260.

21. Briant, 1989; García Sánchez, 2007 y 2009. 
vestir greco-romano de la toga se presenta como un argumento clave sobre el que construir un discurso peyorativo que fundamente la superioridad cultural y civilizatoria greco-romana, frente a la barbarie persa y parta. Hasta tal punto este discurso fue asimilado, que será trasladado posteriormente desde la realidad histórica de los enemigos orientales, a la construcción de una imagen de los otros enemigos literarios ${ }^{22}$ como podrán ser las amazonas o los troyanos.

De entrada, la presencia del pantalón como elemento visual más relevante, no solo venía a representar la oposición entre modelos culturales de entender la manera de cubrir la desnudez del cuerpo. Como bien ha señalado Miller, ${ }^{23}$ el pantalón visualiza dos concepciones enfrentadas de entender la moda. En este caso, a partir del esquema de Barthes $^{24}$ existiría un tipo de vestidura que se podría denominar vertical, que correspondería a la persa, donde el cuerpo es cubierto de arriba abajo (o viceversa) y un modelo horizontal, de superposición de prendas a la manera greco-romana. Pero esta oposición no se limitaría a una cuestión meramente de modas, sino que también ( $\mathrm{y}$ parece que por encima de todo) los griegos estarían señalando una oposición radical en dos maneras enfrentadas de entender el propio arte de la guerra: la desnudez griega frente a la sobre-vestimenta persa. Desde este esquema mental, resulta factible asumir que, para los griegos, el pantalón representaba la esencia del simbolismo etnográfico de lo persa; es decir, lo extranjero: más claramente, lo bárbaro.

El uso del pantalón por parte de persas, medos y demás pueblos del imperio aqueménida constituyó para los autores griegos un elemento en torno al que poder articular un discurso de alteridad fuertemente peyorativo. El choque cultural de esta prenda debió ser tan significativo que estaba presente de manera cotidiana en las representaciones teatrales como forma de generar un motivo de burla o broma fácil con la que ridiculizar a los persas. ${ }^{25}$ La manera popular de referirse al anaxyrides

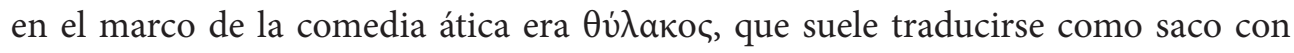
el que cubrir las piernas. Eurípides (Cyc. 182) la incorpora en su representación de Paris y Aristófanes ( $V$. 1087) lo introduce en la forma de referirse a la vestimenta de los soldados persas: "luego los perseguimos, tirándoles el arpón a los calzones ( Tov̀ $\theta 0 \lambda$ ákouৎ), y ellos se daban a la fuga”. ${ }^{26}$ Pero mucho más relevante fue el hecho de que en el imaginario griego, el uso del anaxyrides acabara siendo asimilado al estereotipo

22. Castriota, 2005; Miller, 2006, p. 128; García Sánchez y Albadalejo, 2014, p. 61

23. Miller, 1997, p. 185.

24. Barthes, 1968.

25. Grand-Clement, 2013, pp. 208-209.

26. Traducción L. Macía Aparicio, Madrid, 2007. 
de "afeminado" que desde las Guerras Médicas comienza a convertirse en un discurso permanente con el que simplificar la imagen del bárbaro persa (Xen., Cyr. VIII.8.15):

"Son hoy también mucho más flojos que en tiempos de Ciro, ya que entonces conservaban todavía la educación y el dominio de sí mismos originarios de los persas, junto al modo de vestir y el lujo de los medos; ahora, en cambio, han permitido que se desvanezca la fortaleza de los persas y conservan sólo el afeminamiento de los medos". ${ }^{27}$

Esta percepción afeminada y negativa vinculada al uso de pantalones quedó tan asimilada a la mentalidad griega, que en el momento en que Alejandro Magno termina la conquista del imperio aqueménida y comienza su proceso de asimilación particular hacia las costumbres persas, se abstuvo de forma tajante al uso de esta prenda. Para evitar cualquier confusión, Alejandro rechazó expresamente ${ }^{28}$ el uso del anaxyrides, improvisando un estilo de vestir propio a medio camino entre lo medo y lo persa. Diodoro Sículo $(77,5)$ y Plutarco (Moralia 329f-330a) lo dejan bastante claro:

"De allí se replegó en dirección a la tierra de los partos donde, demorándose por un

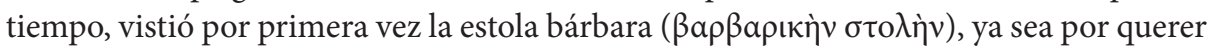
acomodarse a las costumbres vernáculas - pues la comunidad de hábitos y de raza es de gran importancia para domar a los pueblos -, ya sea como un intento subrepticio de imponer la prosternación a los macedonios, acostumbrándoles poco a poco a tolerar los cambios y mudanzas en su género de vida. Ahora bien, no llegó a adoptar el traje de los

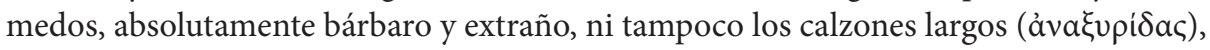
ni la ropa con mangas, ni la tiara, sino que hizo una mezcla acertada, a medio camino por así decir entre el traje persa y el medo, algo menos fastuoso que aquél pero más imponente que éste (...) Este espectáculo contrariaba mucho a los macedonios, pero como por lo demás admiraban sus virtudes, consideraban que debían pasarle por alto algunas de sus inclinaciones al placer o a la vanidad". 29

Si determinante había sido la relación entre el uso de pantalones y la falta de hombría que los griegos habían establecido, no solo en su literatura, sino también en

27. Traducción Ana Vegas, Madrid, 1987.

28. Sobre las interpretaciones en torno a la motivación que pudo estar detrás de la decisión de Alejandro, nos remitimos a Collins, 2012; Amaral Biazotto, 2014; Charles y Agnasnotou, 2016. No deja de ser interesante la acusación que realiza Tertuliano (De pallio 4,6 ), quien no tiene reparos en señalar que Alejandro adoptó sin ningún cuestionamiento el pantalón (sarabara), como una manera de reprocharle que acabó asimilando la cultura meda que él había vencido con sus conquistas.

29. Plut., Alex. 45, 2 (traducción Jorge Bergua, Madrid, 2007). 
la iconografía y representaciones del contraste greco-persa; esta ecuación no desapareció cuando posteriormente fueran los romanos quienes asumieran el protagonismo político y cultural en el ámbito mediterráneo. En este caso, la construcción del discurso de la alteridad bárbara correspondió a quienes habían sustituido a los persas al frente del imperio próximo oriental: los partos. A partir de Augusto, vamos a encontrar un esfuerzo sistemático de parte de Roma por focalizar en el parto el estereotipo del "bárbaro", que unos siglos atrás había correspondido al enemigo por antonomasia de entonces: los cartagineses. ${ }^{30}$ Los partos ocupan el lugar central en la construcción de un enemigo exterior sobre el que focalizar la oposición cultural y su forma de vestir facilitará que se les pueda excluir del concepto de "nación de la toga"; de manera que volvemos a comprobar que el tipo de ropajes y la opción de llevar o no las piernas al aire encierra una carga ideológica. ${ }^{31}$ Los gobernantes partos habían adoptado hasta el punto de integrarlo plenamente el modo de vestir de túnica y pantalones que habían generalizado los medos y los persas, como señala Estrabón (XV 3, 19):

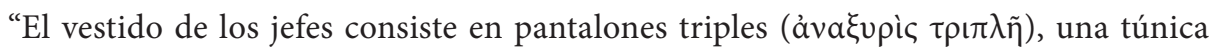
doble con mangas hasta las rodillas; la prenda inferior es blanca, la parte superior de un color variado. La capa para el verano es de color púrpura o violeta, pero para el invierno de un color abigarrado. Los turbantes son similares a los de los magos; y un zapato doble profundo. La generalidad de la gente lleva una doble túnica que llega hasta la mitad de la pierna. Una pieza de lino fino se envuelve alrededor de la cabeza. Cada persona tiene un arco y una honda". ${ }^{32}$

De hecho, habían dado un paso más en este tipo de moda de vestir, para convertir lo que hemos señalado como "ropa de montar" en el periodo aqueménida, en la ropa ceremonial de la corte ${ }^{33}$ (conocido ahora como traje parto), que con los arsácidas acabará siendo asimilada por las demás monarquías helenísticas de la región de Asia Menor y posteriormente será continuada por los persas sasánidas. Nos llama la atención cómo parece que algunos autores le dedican una atención particular no solo a las vestiduras, sino a la calidad de las telas utilizadas, puesto que hasta el momento

30. Moreno, 2012, pp. 63-90; González Román, 2004. Como señala Makhaliuk (2015, p. 301), los romanos asumieron de los griegos todos los clichés, topoi y estereotipos anti-persas para luego transferirlos a los partos, con quienes tenían relaciones complejas.

31. Sobre los ejemplos puestos por los romanos, Albadalejo y García Sánchez, 2014, pp. 61-62. La duración de esta imagen se prolongará incluso hasta el propio periodo bizantino, Rose, 2005, pp. 21-75; López, 2007; Canepa, 2009, pp. 34-36.

32. Traducción S. Torallas, Madrid, 2015.

33. Curtis, 2017, pp. 52-55. 
este aspecto no había sido relevante. Sin embargo, parece que la mayor ornamentación y lujo en las piezas de ropa de los partos y los sasánidas (Hdn., VI 4, 4; Amm. Marc., XVIII 6, 22; XIX 1, 3; S.H.A., Aur. 28, 4-5; 29, 2) facilitó y fomentó que los romanos pudieran continuar la trasferencia del carácter afeminado en el uso de pantalones por parte de sus "bárbaros de oriente". Por tanto, el proceso de transferencia de esos clichés sobre el bárbaro oriental no se sustenta ya entrado el siglo II d.C. en la mera repetición de los tópicos griegos. Parece que, en el contexto romano, ellos mismos han asimilado y reformulado esta acusación sobre la "hombría" de los iranios. Esa es la impresión que transmite Plutarco (Crass. 24, 2) al describir el encuentro entre Craso y el general parto Surena:

"El propio Surena, sin embargo, era el más alto y el más justo de todos, aunque su belleza afeminada no correspondía a su reputación de valor, pero ya estaba más vestida a la manera de los medos, con la cara pintada y el cabello separado, mientras que el resto de los partos aún llevaban el pelo largo y recogido en sus frentes, a la manera de los escitas, para que parecieran formidables" ${ }^{34}$

\section{Presencia del anaxyrides en la iconografía mitraica}

La ausencia de fuentes escritas procedentes del propio ámbito del culto mitraico ha sido la causante de que la iconografía que nos ha llegado a través de la arqueología se haya convertido en la principal vía de documentación y conocimiento de las particularidades del mitraísmo. Hay que reconocer también que esta práctica religiosa se apoyó de forma bastante recurrente en una serie de motivos iconográficos que desempeñaban un papel fundamental a la hora de establecer un discurso mitológico central en la adoración de esta divinidad. La centralidad y la omnipresencia de la representación antropomorfizada de Mitra es incuestionable a la hora de definir este culto, y en la vertebración del canon iconográfico mitraico es fundamental que se le represente con una serie de elementos que en la mayoría de los casos se repiten de manera constante.

La identificación de la representación del dios a través del uso de la vestimenta que se ha venido a llamar "oriental" es fundamental, a la hora de distinguirlo de cualquier otra posible divinidad. De hecho, no es solamente Mitra quien aparece representado en los mitreos con esta apariencia, sino que sus dos acompañantes divinos,

34. Traducción Jorge Bergua, Madrid, 2007. 
Cautes y Cautópates, portan la misma indumentaria. La posibilidad de encontrar a Mitra vestido con estas ropas en los diferentes episodios míticos de su relato de salvación está profusamente documentada en todos los formatos posibles en los que la iconografía mitraica encontró soporte:

- $\quad$ estatuas con la escena de la tauroctonía (CIMRM I, 12; 37; 40; 76; 81; 92; 164)

- pinturas murales de la tauroctonía (CIMRM I, 181;337; 390)

- relieves en placas de bronce, vasos o anillos (CIMRM I, 207; 318; 908; 1206; 1727 ; 2367)

- bajo relieves en mármol (CIMRM I 75; 88; 93; 174; 339; 350; 435; 554; 650)

- Mitra taurophoro (CIMRM II 1495; 1283)

- Mitra con el Sol (CIMRM I 49; II, 1584)

- representaciones de Cautes o Cautópates (CIMRM I 80; 165; 243; 358; 431; $506 ; 636 ; 854)$.

No solo es Mitra o sus ayudantes quienes aparecen con estas ropas, sino que encontramos casos en los que bien personajes particulares, como ocurre en el mitreo de Dura-Europos (CIMRM I, 51), grados iniciáticos, como pudo ser el Pater que oficiaba ceremonias de iniciación en el mitreo de Santa Prisca en Roma (CIMRM I, 483), o los personajes representados en los frescos del mitreo de Cesarea Marítima ${ }^{35}$ aparecen ataviados de esta manera. Si bien, parecen contextos totalmente diferenciados: en Palmira, ${ }^{36}$ se estaría vistiendo a la moda corriente de la zona; en Roma, estaríamos ante un caso de evocación ritual o simbólica a la propia figura de la divinidad. Como parte esencial de este tipo de vestimenta, la presencia del anaxyrides es permanente en todas estas representaciones, tanto en Mitra como en sus ayudantes. ${ }^{37}$ Son escasas las excepciones que se conocen a este modelo canónico de representación mitraica y no parecen responder a una variación significativa en el canon, sino a reaprovechamientos o casos aislados. Dentro de las temáticas señaladas arriba, encontramos una

35. Bull, 2017, pp. 41-44.

36. Curtis, 2017, p. 65.

37. Queda fuera de nuestro estudio en este momento cuestiones anexas a los demás elementos directamente vinculados a la indumentaria con la que se podría representar a Mitra o que pudieran llevar los oficiantes del culto. Parece evidente que, junto con el tipo de las prendas en sí, también sería determinante la relevancia de la presencia de ciertos colores en dichas prendas, como así parece colegirse de los restos que se han conservado en los relieves y pinturas de algunos mitreos, como señala Lissi Carona, 1979, p. 209. Sobre el simbolismo de los colores y su presencia en el contexto mitraico en una posible conexión con el mundo iranio, nos remitimos a Campos, 2004. Más recientemente ha abordado este aspecto García Sánchez, 2012. 
estatua de Mitra tauróctono vestido con una toga (CIMRM I, 230), si bien parece que se trata de una reutilización de la figura. Otros ejemplos presentan a Mitra desnudo, portando tan solo el gorro y una capa (CIMRM I 479); o un caso donde Cautopates aparece vestido con una túnica corta (CIMRM I 477), sin pantalón (CIMRM I 773) o solo con capa y gorro (CIMRM I 951). Donde únicamente se rompe de manera permanente el recurso iconográfico de la vestimenta con anaxyrides es en la representación del motivo del nacimiento del dios de la piedra: petrogénito (CIMRM I $344 ; 353 ; 860 ;$ II 1248; 1492; 1687; 1756; 2134; 2184). Si bien mantiene la tiara como elemento identitario, es significativo que en todas las imágenes que conocemos de este episodio del relato mítico mitraico, ${ }^{38}$ se prescinde de los ropajes característicos para manifestar la desnudez con la que Mitra llega al mundo.

Con independencia de cuál haya podido ser el origen del establecimiento del canon iconográfico de la tauroctonía, parece evidente que los seguidores del culto mitraico asimilaron una representación antropomorfa del dios que había encontrado sus primeras representaciones conocidas en el contexto del reino minorasiático de Comagene, ${ }^{39}$ donde el rey Antíoco I había mandado construir en el año 62 a. C. un túmulo funerario en lo alto del monte Nemrud. En un contexto claramente de sincretismo religioso entre divinidades iranias y griegas, encontramos dos imágenes identificadas claramente con Mitra, donde queda fijado su canon en torno a este tipo de vestimentas, con la presencia inconfundible del anaxyrides. Resulta importante señalar también que en las escasas representaciones que conocemos de Mitra en el contexto sasánida, ${ }^{40}$ la presencia del pantalón será una constante, por encima de otras variaciones locales que podamos encontrar y que refuerzan la idea de un dios cercano a su función en el panteón zoroastriano.

Ha quedado claro, pues, que a la hora de establecer por parte de los seguidores mitraicos los elementos que conformaban la seña de identidad de su divinidad, era la presencia de este tipo de vestimenta la que actuaba como un factor determinante. Hasta tal punto esto estaba asimilado, que encontramos referencias literarias donde la evocación a cualquiera de los elementos que estaban presentes en el descrito como "vestido oriental", servía como medio para referirse a esta divinidad. Mitra es el "deus pileatus" al que hace referencia Agustín de Hipona (Trat. Evang. Juan VII 6); pero también es descrito como "persico habitu" por Estacio (Theb. I

38. Sobre la especificidad de este motivo iconográfico y su significado en el culto, Álvarez-Pedrosa, 2016.

39. Schwertheim, 1975, pp. 63-68; Dörner, 1978, pp. 123-133; Elsner, 2017.

40. Azarpay, 1982, pp. 181-191; Callieri, 1990, pp. 79-98; Overlaet, 2012, pp. 133-151.

ARYS, 17, 2019 [227-249] ISSN 1575-166X 
700) o el que "lleva el kandys y la tiara", como le señala Luciano (D.Deor. IX). De qué manera afectaba o gestionaban los seguidores de Mitra la aceptación como dato cotidiano de un elemento que contenía una carga peyorativa negativa es algo que no podemos reconocer de manera directa. Esta es la razón por la que nos ha parecido pertinente tratar de identificar cuál pudo ser el contexto particular en el que un elemento como el pantalón, que en un marco genérico era percibido como sinónimo de anti-romanidad, pudiera ser asimilado aparentemente sin conflictos significativos. No podemos excluir la posibilidad de que los factores que lograron permitir la aceptación de una representación del dios Mitra con estos atuendos "orientales", no actuaran, posiblemente, de manera exclusiva en la mentalidad de los seguidores de Mitra, sino que también consiguieron participar en la normalización de las otras divinidades representadas con estos atuendos. Sin embargo, nos parece relevante que la cuestión de la presencia de estos elementos visibles en relación con Mitra fueran una constante a la hora de identificar el culto o su iconografía. La permanencia de estas referencias a la indumentaria de Mitra a lo largo del tiempo, nos dan a entender que, a pesar de su integración en términos generales en la mentalidad romana, visualmente continuó siendo un elemento anómalo; ${ }^{41} \mathrm{de}$ ahí que, si comprendemos los mecanismos que pudieron utilizar los mitraistas al respecto, podamos obtener una visión de conjunto al respecto.

Como hemos indicado, no resulta posible identificar de forma única este proceso de asimilación de este elemento visual y cultural. Se nos plantea una diversidad de contextos o escenarios para poder comprender que la presencia de una prenda de vestir, como era el pantalón, que en la vida ordinaria romana estaba revestida de una carga ideológica tan negativa, llegara a ser integrada, asimilada y no cuestionada en este caso por los seguidores mitraicos. Dada la imposibilidad de poder llegar a conocer cuál fue el mecanismo de integración y relación cotidiana de los mitraistas con el visionado de esta prenda, entendemos que pudieron ser diferentes las respuestas realizadas para gestionar un posible conflicto en torno al pantalón y que debía encontrar su acomodo en el recinto sagrado del interior del mitreo, puesto que, como sabemos, el mitraísmo careció a lo largo de su historia de proyección pública alguna.

41. Todavía en época bizantina podemos encontrar referencias de cómo el uso de pantalones (anaxyrides) se podía convertir en un argumento con el que criticar la hombría de un individuo. Así lo vemos en el obispo del siglo XII Eustacio de Tesalónica (Comm. Iliad. I 36, 11; 328, 28-29) quien menciona su uso con cierta desaprobación y junto con el historiador Coniates $(298,30-32)$ utilizan el uso de esta prenda para atacar al gobernador de Tesalónica David Comneno. Para contextualizar este episodio, cf. Bravo y Álvarez, 1988, pp. 106-107. 
Un primer escenario, y el más sencillo, para comprender esta problemática podría ser que directamente este elemento fuera intencionalmente ignorado por los iniciados en el culto. De manera que, si no debió suponer un problema significativo la propia procedencia oriental de Mitra, tampoco parece que debiera ser este un aspecto que acentuara un rechazo explícito por parte de los romanos que se acercaran a este culto. Sin embargo, el hecho de que este tema fuera un factor subrayado por quienes desde fuera ejercieron una significativa hostilidad contra el mitraísmo (circunstancia que no hemos encontrado que fuera denunciada de manera explícita en las demás divinidades mencionadas), nos hace suponer que las vestimentas con las que Mitra era representado no dejaban de ser una circunstancia que pudiera ser ignorada fácilmente. Más aún, si como hemos indicado arriba, fuera muy probable que en diferentes ceremonias celebradas en el interior de los mitreos más de un iniciado apareciese vistiendo este tipo de ropajes como parte de la liturgia a modo de evocación directa de la figura del dios. Además, la procedencia pérsica del dios fue un argumento recurrente de ataque entre los Padres de la Iglesia. Orígenes (Cels. 622) habla de los misterios de los persas en su argumentario contra Celso. Ya hemos mencionado al obispo de Hipona (Trat. Evang. Juan VII 6) utilizar la expresión "deus pileatus" y Fírmico Materno (Err. prof. relig. 5, 2) lo señala sin ningún tipo de reparos:

"Entonces, ¿qué respetas? En sus templos (se observa) rigurosamente (la liturgia) de los magos según el rito pérsico, ¿por qué no alabas a los persas más que en sus prácticas? Si te juzgas digno del nombre romano, qué haces sirviendo así las liturgias de los persas, las leyes de los persas".42

Un segundo escenario, que se complementa con el anterior, podría ser el que hubiera habido una voluntad expresa de aceptar sin mayores cuestionamientos la forma de vestir del dios, incluyendo el pantalón, con el fin de fortalecer ese rasgo de exotismo que se quería señalar en relación con el culto mitraico, en el contexto de las demás religiones mistéricas que se están difundiendo por el Imperio. Estaríamos ante el desarrollo interesado de un "persianismo", como ha señalado Gordon: ${ }^{43}$ "to the degree that such 'mystagogues' were interested in exploiting the Persian origin of Mithras, they thought of themselves as affirming a fact given by the iconography, or, more vaguely, the tradition they inherited". Desde este marco, podríamos entender que la relación que los iniciados mitraicos establecerían con los elementos que

42. Trad. propia.

43. Gordon, 2017, p. 314. 
identifican y fortalecen el carácter "pérsico" del dios (entre ellos el "persico habitu" de Estacio - Theb. I 700 -, incluyendo los anaxyrides), no debía suponer ningún tipo de escrúpulo cultural, sino que eran integrados dentro del paquete global que suponía asumir la especificidad y exotismo de Mitra, como oferta religiosa alternativa al modelo tradicional representado por el panteón romano clásico.

Para ahondar en la comprensión de esta relación, podemos señalar también, que con independencia de la carga ideológica que podía recibir esta prenda dentro de un contexto cultural determinado e interesado, hemos indicado que el canon iconográfico que el mitraismo incorpora tiene una relación más estrecha con la representación antropomorfa de Mitra procedente del contexto geográfico de Asia Menor, que de Persia o Partia propiamente. Es en este contexto geográfico donde se había producido una mayor y más clara fusión de los elementos identitarios greco-iranios, hasta el punto de que, en poblaciones con un origen cultural heleno, había llegado a normalizarse la adopción de prendas de vestir que tenían una connotación inicialmente peyorativa. Está atestiguado ${ }^{44}$ que, en las ciudades jonias, era frecuente desde finales del periodo aqueménida que la población vistiera en ocasiones señaladas prendas que formaban parte del mal llamado "traje medo". Esta circunstancia facilitó que en la configuración de los reinos helenísticos minorasiáticos, la adopción de estas prendas pudiera quedar normalizada, hasta el punto de que el kandys, la tiara y el anaxyrides constituyeran las vestimentas que conformaban la ropa ceremonial real. ${ }^{45}$ Muy posiblemente, esta consideración es la que está presente en la elección de los elementos que configuran las representaciones de Mitra en el recinto santuario del monte Nemrud del reino de Comagene. Por tanto, podríamos inferir que la incorporación del canon iconográfico mitraico con estos rasgos definitorios dentro de contexto romano podría haberse producido ya vaciado de cualquier vinculación directa con el ámbito persa.

Por último, y con vistas a considerar otros contextos en los que la prenda del pantalón pudiera facilitar su aceptación por parte de los seguidores de Mitra, encontramos que, dentro de la propia sociedad romana, ajeno a los intereses propagandísticos puntuales, se había ido produciendo progresivamente la difusión de una prenda de vestir muy cercana al anaxyrides. Es en el contexto militar romano, tan cercano a la masa social que se acerca al mitraismo, donde se ha podido constatar que desde el siglo I d.C. se ha integrado el pantalón desde una perspectiva funcional, ${ }^{46}$ especial-

44. Miller, 2013, pp. 22-23.

45. Curtis, 2017, p. 53.

46. Charles, 2002, pp. 691-692; Menéndez, 2010, p. 247. 
mente para las tropas que estaban destinadas en territorios más fríos del Imperio. El uso de los denominados como "braccae", "feminalia" o "femoralia" pudo ser adoptado por las legiones romanas a partir del contacto con las tropas auxiliares de las regiones orientales y del norte de Europa; pero parece claro que su uso se generalizó a partir del siglo III d.C., hasta estar presente en la ropa de algunos emperadores (S.H.A., Seuer. 40, 11). Es, por tanto, el ámbito militar el espacio que va a facilitar que el uso de una prenda como el pantalón pueda ser sustraído de su connotación peyorativa; especialmente si vemos que fuera de ese contexto, continuarán existiendo restricciones al uso de esta prenda, como la prohibición que hacen Arcadio y Honorio de vestir "bracae" en Roma (CTh. 14, X, 2). Este contexto específico podría ser también relevante para terminar de comprender que, con independencia de las intenciones de fomentar un toque de "persismo" como distinción particular del mitraísmo, ya existía un espacio genérico consensuado que facilita que los hombres que se iniciaban en los misterios mitraicos no experimentaran ningún tipo de rechazo hacia la representación iconográfica de Mitra. El uso funcional y la normalización del pantalón desde un contexto tan concreto como el militar pudo facilitar que adorar a un dios que se vestía por los pies pudiera ser plenamente despojado de cualquier tipo de carga cultural peyorativa, y que así no entrara en conflicto con el apelativo de "invictus" que estaba tan firmemente asociado el dios del "persicu habitu".

\section{Conclusiones}

Como hemos tratado de señalar, existió a lo largo del periodo greco-romano una relación de hostilidad peyorativa en torno a un modelo de vestimenta que había sido asimilado con la imagen del bárbaro oriental. La referencia al uso de estas prendas sirvió tanto desde la literatura, como en la iconografía para ejemplificar la oposición cultural entre lo que significaba ser griego o romano en oposición al enemigo persa o parto. Sin embargo, la introducción dentro del marco religioso romano de ciertas divinidades que por su procedencia oriental aportaban también un canon visual determinado pudo obligar a revisar o acomodar estos clichés culturales. Hemos tratado de plantear diferentes escenarios en los que dentro de una de esas nuevas prácticas religiosas se pudo producir este proceso de asimilación e integración. El caso del mitraísmo es relevante porque la adopción de estas prendas, particularmente el pantalón, no se limitó solo a la representación de la divinidad, sino a su incorporación como vestimenta litúrgica de forma puntual. Esto hacía que ya no fuera solo un elemento vinculado con la imagen de la divinidad, sino una prenda a ser llevada por algunos de los iniciados. Los diferentes contextos que hemos planteado podrían haber facilitado 
la normalización de la presencia del anaxyrides dentro de un marco específico como sería el religioso, cuando los demás testimonios nos siguen mostrando que la suspicacia y el rechazo hacia esta prenda en el ámbito público siguió presente incluso caído ya el imperio romano. De esta forma, hemos comprobado cómo la religión permite a una comunidad o a un grupo crear un lenguaje propio con los conceptos, las ideas o los objetos para relacionarse con ellos al margen del significado, función o carga ideológica que puedan tener en el contexto cotidiano general. 


\section{Abreviaturas}

CIMRM: Vermaseren, M. (1956-1960). Corpus Inscriptionum et Monumentorum Religionis Mithriacae. La Haye: Martinus Nijhoff.

\section{Bibliografía}

Albadalejo Vivero, M. y García Sánchez, M. (2014). Luxuria et mollitia: Rome’s textile raw material trade with the East. En Alfaro, 2014, pp. 57-66.

Alfaro, C. (ed.) (2014). Production and Trade of Textiles and Dyes in the Roman Empire and Neighbouring Regions. Valencia: Universitat de València.

Alfaro, C. y Ortíz, J. (eds.) (2014). Tiarae, Diadems and Headdresses in the Ancient Meditarranean Cultures. Symbolism and Technolgy. Valencia: Universitat de València.

Alvar, J. (2008). Romanising oriental Gods: myth, salvation and ethics in the cults of Cybele, Isis and Mithras. Leiden: Brill.

Alvar, J. (2017). The 'Romanization' of 'Oriental Cults'. En Nagel, Quack y Witschel 2017, pp. 23-46.

Álvarez-Pedrosa, J.A. (2016). El dios que nace de la roca. Aspectos comparativos del mito del nacimiento de Mitra. Emerita, Revista de Lingüística y Filología Clásica, 84.2, pp. 317331.

Amaral Biazotto, T. (2014). Sobre vestes bárbaras, calças e tiaras: poder e alteridade na adoção de trajes estrangeiros por Alexandre Magno na Vida de Alexandre, de Plutarco. Romanitas. Revista de Estudos Grecolatinos, 11, pp. 182-201.

Armayor, K. (1978). Herodotus' Catalogues of the Persian Empire in the Light of the Monuments and the Greek Literary Tradition. Transactions of the American Philological Association, 108, pp. 1-9.

Azarpay, G. (1982). The role of Mithra in the investiture and triumph of Shapur II. Iranica Antiqua, 17, pp. 181-191.

Azoulay, V. (2004). The Medo-Persian Ceremonial: Xenophon, Cyrus and the King's Body. En Tuplin, 2004, pp. 147-173.

Barringer, J. (ed.) (2005). Periklean Athens and its legacy: problems and perspectives. Austin: University of Texas.

Barthes, R. (1968). Système de la mode. Paris: Seuil.

Beck, R. (2004). Beck on Mithraism. Hampshire: Routledge.

Bianchi, U. (ed.) (1979). Mysteria Mithrae. Leiden: Brill.

Boehringer, S. y Sebillotte, V. (eds.) (2013). Des femmes en action, L' individu et la fonction en Grèce ancienne. Paris: EHESS.

Bravo, A. y Álvarez, J. (1988). La civilización bizantina de los siglos XI y XII: Notas para un debate todavía abierto. Erytheia, 9.1, pp. 77-132. 
Briant, P. (1989). Histoire et idéologie. Les Grecs et la 'décadence perse’. En Mactoux y Geny, 1989, pp. 33-47.

Bull, R.J. (ed.) (2017). The Mithraeum at Caesarea Maritima. Boston: The American Schools of Oriental Research.

Callieri, P. (1990). On the Diffusion of Mithra images in Sasanian Iran; New Evidence from a Seal in the British Museum. East \& West, 40, pp. 79-98.

Campos, I. (2004). Consideraciones sobre el origen de la iconografía de los misterios mitraicos. Florentia Iliberritana, 15, pp. 9-28.

Campos, I. (2017a). Palabras persas en el mitraísmo: la construcción de una imagen oriental del culto mitraico. Espacio, Tiempo y Forma. Ha Antigua, 30, pp. 45-64.

Campos, I. (2017b). Panorámica historiográfica de los estudios sobre el Mitra védico, avéstico y romano. Revista de historiografía, 28, pp. 265-286.

Canepa, M. (2009). The Two Eyes of the Earth Art and Ritual of Kingship between Rome and Sasanian Iran. San Francisco: University of California Press.

Castriota, D. (2005). Feminizing the Barbarian and Barbarizing the Feminine: Amazons, Trojans, and Persians in the Stoa Poikile. En Barringer, 2005, pp. 89-102.

Charles, M. (2002). The Flavio-Trajanic miles: the Appearance of Citizen Infantry on Trajan's Column. Latomus, 61.3, pp. 666-695.

Charles, M. y Anagnostou, E. (2016). Athenaeus, Clearchus and the dress of the Persian Apple bearers. Iranica Antiqua, 51, pp. 149-164.

Collins, A. (2012). Alexander and the Persian court chiliarchy. Historia. Zeitschrift für Alte Geschichte, 61.2, pp. 159-167.

Cumont, F. (1903). Les mysteries de Mithra. Brussels: Lamertin.

Cumont, F. (1906). Les religions orientales dans le paganisme romaine, Paris: E. Leroux.

Curtis, V. (ed.) (2007). The Age of the Parthians. London: I.B. Tauris.

Curtis, V. (ed.) (2010). The World of Achaemenid Persia: History, Art and Society in Iran and the Ancient Near East. London: I.B. Tauris.

Curtis, V. (2017). The parthian haute-costure at Palmyra. En Long, 2017, pp. 52-67.

Della Casa, P. (ed.) (2013). Tattoos and Body Modifications in Antiquity. Proceedings of the sessions at the EAA annual meetings in The Hague and Oslo, 2010/11. Zurich: Chronos Verlag.

Dörner, F. (ed.) (1975). Kommagene, Geschichte und Kultur einer antiken Landschaft. Küsnacht: Raggi-Verlag.

Dörner, F. (1978). Mithras in Kommagene. En Duchesne-Guillemin, 1978, pp. 123-133.

Duchesne-Guillemin, J. (1978). Études Mithriaques. Leiden: Brill.

Elsner, J. (ed.) (2017). Images of Mithra. Oxford: OUP.

Fornis, C. (ed.) (2013). Los discursos del Poder. El poder de los discursos en la Antigüedad Clásica. Zaragoza: Pórtico.

García Sánchez, M. (2007). Los bárbaros y el Bárbaro: identidad griega y alteridad persa. Faventia, 29.1, pp. 33-49. 
García Sánchez, M. (2009). El Gran Rey de Persia: formas de representación de la alteridad persa en el imaginario griego. Barcelona: Publicacions i Edicions, Universitat de Barcelona.

García Sánchez, M. (2012). The dress and colour of Mithraism: Roman or Iranian garments? En Schrenk, 2012, pp. 123-134.

García Sánchez, M. (2013). El discurso sobre el bárbaro: Aqueménidas, Arsácidas y Sasánidas en las fuentes grecorromanas. En Fornis, 2013, pp. 73-110.

García Sánchez, M. y Albadalejo Vivero, M. (2014). Diademas, tiaras y coronas de la Antigua Persia: formas de representación y de adopción en el mundo clásico. En Alfaro y Ortíz, 2014, pp. 79-94.

Gnoli, T. y Muccioli, F. (eds.) (2007). Incontri tra culture nell'Oriente ellenistico e romano. Milano: Mimesis.

González Román, C. (2004). La imagen de Cartago: estereotipos y realidad histórica. Florentia Iliberritana, 15, pp. 115-133.

Gordon, R. (1975). Franz Cumont and the Doctrines of Mithraism. En Hinnells, 1975, pp. 215-248.

Gordon, R. (2014). Coming to Terms with the 'Oriental Religions of the Roman Empire'. Numen, 61, pp. 657-672.

Gordon, R. (2017). Persae in Spelaeis Solem colunt: Mithra(s) between Persia and Rome. En Strootman y Versluys, 2017, pp. 279-315.

Grand-Clément, A. (2013). Porter la culotte : enquête sur l' imaginaire du pantalon dans le monde grec. En Boehringer y Sebillotte, 2013, pp. 199-216.

Heuzey, L. (1935). Histoire du costume dans l'Antiquité classique. L'Orient (Egypte, Mésopotamie, Syrie, Phénicie). Paris: Les Belles Lettres.

Hinnells, J. (ed.) (1975). Mithraic Studies. Manchester: Rowman and Littlefield.

Ilarraga, R. (2017). Los Modos de la Corte. La Formación Meda de Ciro en Ciropedia. Revista Portuguesa de Filosofia, 73.3-4, pp. 1607-1642.

Lissi Carona, E. (1979). La rilevanza storico-religiosa del Materiale Mitriaco dei S. Stefano Rotondo. En Bianchi, 1979, pp. 205-218.

Llewelyn-Jones, L. (2013). King and Court in Ancient Persia 559-331 B.C. Edimburg: University Press.

Long, T. (ed.) (2017). Positions and Professions in Palmyra. Selskab: The Royal Danish Academy of Sciences.

López, D. (2007). Before your very eyes. Roman imperial ideology, gender constructs and Paul's inter-nationalism. En Penner, 2007, pp. 115-162.

Mactoux, M., Geny, E. (1989). Mélanges Pierre Lévêque. Tome 2: Anthropologie et société. Paris: Les belles lettres

Makhaliuk, A. (2015). Memory and Images of Achaemenid Persia in the Roman Empire. En Silverman y Waerzeggers, 2015, pp. 299-324.

Menéndez, R. (2010). La Guardia Pretoriana en combate I: equipamiento. Habis, 41, pp. 241 261.

Merkelbach, R. (1984). Mithras. Stuttgart: Hain. 
Miller, M. (1997). Athens and Persia in the Fifth Century BC: A Study in Cultural receptivity. Cambridge: Cambridge University Press.

Miller, M. (2006). Orientalism and Ornamentalism: Athenian Reactions to Achaemenid Persia. Arts. The Journal of the Sydney University Arts Association, 28, pp. 117-146.

Miller, M. (2013). Clothes and Identity: The Case of the Greeks in Ionia c. 400 BC. Antichthon, 47, pp. 18-38.

Moreno, A. (2012). Interpretando el mundo romano: retórica de la alteridad, público y cultura griega en las Historias de Polibio. Gerión, 30.1-2, pp. 63-90.

Muccioli, F. (2007). La rappresentazione dei Parti nelle fonti tra II e I secolo a.C. e la polemica di Livio contro i levissimi ex Graecis. En Gnoli y Muccioli, 2007, pp. 87-115.

Nagel, S., Quack, J. y Witschel, C. (eds.) (2017). Entangled Worlds: Religious Confluences between East and West in the Roman Empire The Cults of Isis, Mithras, and Jupiter Dolichenus, Tübingen: Mohr Siebeck GmbH \& Co.

Overlaet, B. (2012). Ahura Mazda and Shapur II? A note on Taq-I Bustan I, the investidure of Ardashir II, (379-383). Iranica Antiqua, 47, pp. 133-151.

Penner, T. (ed.) (2007). Mapping Gender in Ancient Religious Discourses. Leiden: Brill.

Rose, C. (2005). The Parthians in Augustan Rome. American Journal of Archaeology, 109.1, pp. 21-75.

Saxl, F. (1931). Mithras: Typengeschichtliche Untersuchungen, Berlin: Keller.

Schneider, R. (1986). Bunte Barbaren. Orientalenstatuen aus farbigem Marmor in der römischen Repräsentationskunst. Worms: Werner.

Schneider, R. (2007). Friend and Foe: the Orient in Rome. En Curtis, 2007, pp. 50-86.

Schrenk, S. (ed.) (2012). Kleidung und Identität in religiösen Kontexten der römischen Kaiserzeit. Bonn: Schnell \& Steiner.

Schwertheim, E. (1975). Monumente des Mithraskultes in Kommagene. En Dörner, 1975, pp. 63-68.

Sekunda, N. (2010). Changes in Achaemenid Royal Dress. En Curtis, 2010, pp. 256-272.

Sierra, R. y Campos, I. (2010). Actuación de los magistrados en la introducción de los Cultos Orientales en Roma. En Suárez, 2010, pp. 55-66.

Silverman, J. y Waerzeggers, C. (eds.) (2015). Political memory in and after the persian empire. Atlanta: SBL Press.

Strootman, R. y Versluys, M. (2017). Persianism in antiquity, Stuttgar: Steiner Franz Verlag.

Suárez, E. (ed.) (2010). Lex Sacra: Religión y Derecho a lo largo de la Historia. Valladolid: SECR.

Thomson, G. (1965). Iranian Dress in the Achaemenian Period: Problems concerning the Kandys and Other Garments. Iran, 3, pp. 121-126.

Tuplin, C. (2004). Xenophon and his world: Papers from a Conference held in Liverpool in July 1999. Stuttgart: Franz Steiner Verlag.

Ulansey, D. (1989). The origins of the Mithraic Mysteries. Cosmology \& Salvation in the Ancient World. New York: OUP. 
Widengren, G. (1956). Some remarks on Riding Costume and Articles of Dress among Iranian Peoples in Antiquity. Arctica. Studia Etnografica Upsaliensa, 11, pp. 228-276.

Yatsenko, S. (2013). The Tattoo System in the Ancient Iranian World. En Della Casa, 2013, pp. 97-101. 